\title{
Development and Test of a Model of Interdisciplinary Competencies
}

\author{
Anna M. Claus ${ }^{\mathrm{a} *} \&$ Bettina S. Wiese ${ }^{\mathrm{a}}$ \\ ${ }^{\mathrm{a}}$ Institute of Psychology, RWTH Aachen University, Germany
}

This is an Accepted Manuscript of an article published by Taylor \& Francis in European Journal of Work and Organizational Psychology on January 21, 2019, available online: http://www.tandfonline.com/10.1080/1359432X.2019.1567491

Author Note: This research was made possible by a grant from the Federal Ministry of Education and Research in Germany (Grant ID: 16FWN009) to the second author. We gratefully acknowledge this support.

Correspondence concerning this manuscript should be addressed to Anna M. Claus, RWTH Aachen University, Institute of Psychology, Jaegerstrasse 17-19, 52056 Aachen, Germany, email: anna.claus@psych.rwth-aachen.de, phone: +49 24180 93991; ORCiD 0000-0001-8509-3610

Bettina S. Wiese, RWTH Aachen University, Institute of Psychology, Jaegerstrasse 17-19, 52056 Aachen, Germany, email: wiese@psych.rwth-aachen.de 


\section{Development and Test of a Model of Interdisciplinary Competencies}

Interdisciplinary work offers both innovative potential and challenges in collaboration. The present paper summarizes three studies intended to foster a psychological, competency-focused understanding of interdisciplinary work. In a qualitative interview study (Study 1) with expert practitioners of interdisciplinarity, we used the critical incident technique to explore which individual competencies support interdisciplinary collaborations and improve innovative outcomes. Focusing on competencies specific to interdisciplinarity, we derived a four-dimensional model. In Study 2, we tested the model dimensions (1) initiative for exchange, (2) target group-specific communication, (3) knowledge integration, and (4) reflection in a quantitative survey study among $N=$ 315 employees who were experienced in interdisciplinary work using exploratory structural equation modelling. Finally, in Study 3, we studied the convergent and divergent validity of interdisciplinary competencies as well as their role in predicting team outcomes. Here, a dyadic sample of $N=448$ target persons and $N=153$ interdisciplinary colleagues were surveyed. We discuss possible applications for the new model of interdisciplinary competencies and the developed self-report instrument.

Keywords: interdisciplinary competencies; critical incident technique; exploratory structural equation modelling; mixed-method; validation 


\section{Development and Test of a Model of Interdisciplinary Competencies}

Interdisciplinary projects aim for innovation both in academia and the private sector by attending to complex tasks that cannot be adequately addressed by a single discipline alone (Sung et al., 2003). But many interdisciplinary projects cause frustration among team members who find this kind of teamwork particularly difficult (Epstein, 2005). As a result, projects are often divided into separate disciplinary sub-projects, and the innovative potential of integrating different disciplines gets lost (Rogers, Scaife, \& Rizzo, 2005).

Interdisciplinarity is a special case of collaboration. During academic training and work practice, students and employees become socialized in a disciplinary culture and adopt its disciplinary perspective which influences their thinking about tasks, possible solutions, and methods (Reich \& Reich, 2006; Repko, Szostak, \& Buchberger, 2014). The disciplinary background is a deep-level characteristic relevant for teamwork. In the past, researchers have studied specific challenges that interdisciplinary work poses such as communication barriers (Bromme, 2000) and knowledge integration problems (Steinheider, Bayerl, Menold, \& Bromme, 2009). Interdisciplinary work thus poses specific demands on employees.

While previous work has highlighted organizational means and team level characteristics to make functionally diverse and interdisciplinary collaborations successful (Cheung, Gong, Wang, Zhou, \& Shi, 2016; Cronin \& Weingart, 2007; van Ginkel \& van Knippenberg, 2008), competencies of involved employees have received little attention. Nevertheless, individual competencies of team members are an important factor for flourishing interdisciplinary collaborations (Bronstein, 2003; Epstein, 2005). Existing concepts for general teamwork competencies (e.g., Stevens \& Campion, 1994) do not address unique competency requirements for interdisciplinary work. Therefore, they do not provide sufficient guidance in analysing how individuals can positively influence interdisciplinary work. Understanding individual competencies and their impact on interdisciplinary 
collaboration is necessary to develop means to improve project outcomes and to utilize innovative potentials.

We applied a mixed-methods design to develop and test a model of unique interdisciplinary competencies. In doing so, the present studies contribute to theory and knowledge in research on interdisciplinarity in at least two ways: First, we contribute to the theoretical understanding of interdisciplinary collaborations by identifying relevant competency dimensions for interdisciplinary work. Thus, we extend literature on competencies for teamwork situations (Stevens \& Campion, 1994) to the unique requirements of interdisciplinarity. Our second contribution is the development of a model-based instrument to measure interdisciplinary competencies to foster future research.

\section{Interdisciplinary Collaboration}

Interdisciplinarity is defined by a high degree of integration of different disciplinary perspectives (Repko et al., 2014). Disciplinary perspectives represent established bodies of knowledge and modes of thinking within one academic or occupational field. They facilitate work processes within a discipline; however, they also hinder cooperation across disciplines (Sung et al., 2003). Thus, in interdisciplinary collaboration, information, data, methods, and theories associated with the involved disciplines need to be integrated to form a shared project. In this regard, interdisciplinarity differs from other forms of collaboration between disciplines (e.g., multidisciplinarity) which juxtapose disciplinary perspectives (Newell, 2001; Szostak, 2002).

Interdisciplinarity is a special form of functional diversity. Interdisciplinary teams are often built around a certain topic or research question. To deal with the issue at hand, individuals from different disciplines and their expertise are required (e.g., for product development of a shampoo, a chemist, a dermatologist, a beautician, a production engineer, and a business administrator might work together). In diverse teams, socially shared cognition has been shown to influence the process of elaborating distributed information (van 
Ginkel \& van Knippenberg, 2008). The development of shared mental models is supported by increased interaction and communication (Maynard \& Gilson, 2014). However, communication in interdisciplinary teams is challenging, as shared communal experiences based on discipline are lacking. Consequently, interdisciplinary teams need to elaborate and negotiate their common ground that is the basis of mutual knowledge and beliefs (Clark, 1996). In other words, smooth collaboration in interdisciplinary teams requires increased competencies of team members, particularly regarding the communication domain, to create a common ground and shared mental models.

\section{Interdisciplinary Competency}

Competencies refer to sets of behaviours that are instrumental in dealing with an underlying intent (Boyatzis, 2008). We understand interdisciplinary competencies as instrumental sets of behaviour in dealing successfully with interdisciplinary endeavours (see also Brandstädter \& Sonntag, 2016). As such, interdisciplinary competencies extend teamwork competencies (Stevens \& Campion, 1994) to the unique demands of interdisciplinary work settings. Bromme (2000) underlines that individual competencies need to be specific for interdisciplinarity to explain success and failure in interdisciplinary work. This specificity of interdisciplinary competencies refers to an interpretative approach of competencies (Sandberg, 2000) which emphasizes that competencies are mentally constructed by the meaning the employee makes of his or her work. With regard to interdisciplinarity, it makes use of employees' experience that interdisciplinary work is different from other teamwork. In short, interdisciplinary competencies are learned instrumental behaviours, which enable employees to deal with the specifics of working across disciplinary boarders. To a certain degree, they are expected to resemble teamwork competencies such as communication skills or collaborative problem solving (Stevens \& Campion, 1994), but essentially go beyond traditional teamwork competencies to the integrative core of interdisciplinarity. 
In the past, research has dealt with selected challenges of interdisciplinary work and individual competencies to deal with them. Bromme (2000) described communication as a central challenge in interdisciplinary teams, as each person is an expert in her or his own discipline, but a layperson regarding all other disciplines. Hence, communication skills regarding expert-layperson communication influence interdisciplinary outcomes (Bromme, 2000). In addition, the cognitive challenge of integrating diverse bodies of knowledge has been discussed as being characteristic for interdisciplinarity (Steinheider et al., 2009; van Knippenberg, De Dreu, \& Homan, 2004). To reach the goal of innovative interdisciplinary work, it is necessary to use the entire spectrum of information distributed among team members. Thus, knowledge integration is a core task in interdisciplinary teams. Steinheider et al. (2009) consider knowledge integration an individual skill, and found it to be a central predictor for the success of interdisciplinary teams.

The first valuable attempts to integrate different challenges of interdisciplinary work into a requirement or competency model were made by Brandstädter and Sonntag (2016) and by Lattuca, Knight, and Bergom (2012). Based on a requirement analysis, Brandstädter and Sonntag (2016) proposed 40 competency dimensions which cover various traits and abilities (e.g., language adjustment, friendliness, conscientiousness). The strength of completeness in terms of a full array of useful competencies and attributes, however, comes at cost of a lack of specificity: in our view, this model also covers many general teamwork situations. On the other hand, Lattuca et al. (2012) assessed only three interdisciplinary competencies (reflective behaviour, recognizing disciplinary perspectives, and interdisciplinary skills) for learning outcomes in engineering students. Unfortunately, little information is presented regarding the generation of this model and the definitions of these dimensions, especially the interdisciplinary skills dimension. As a consequence, the first models appear to be either 
extremely detailed or not detailed enough in terms of skills to provide a framework for analysing behaviours and its practical use.

To examine which competencies are specific to and relevant in interdisciplinary settings, we chose an inductive analysis of qualitative data for our first study (Study 1). This approach allowed us to use the experiences of interdisciplinary expert practitioners in defining core competencies for interdisciplinary work. In a subsequent survey (Study 2), we attempted to replicate our findings quantitatively. Finally, Study 3 served as a validation study. This mixed-method approach combines the features of qualitative and quantitative methods to identify interdisciplinary competencies (Eisenhardt \& Graebner, 2007).

\section{Study 1: Development of a Model}

The goal of the first study was to inductively develop a model of interdisciplinary competencies based on a requirement analysis for interdisciplinary settings. Thus, a qualitative approach featuring in-depth interviews was chosen. This enables the grounding of model dimensions in the experiences of interdisciplinary practitioners by analysing observations of successful behaviours and deriving specific competency dimensions.

\section{Method and Results}

The development process was based on the critical incident technique (CIT, Flanagan, 1954) as a method for requirement analysis. The CIT offers a systematic approach to analyse and categorize functional behaviours in fulfilling task requirements. A critical incident includes both crucial situational demands and behaviours (Koch, Strobel, Kici, \& Westhoff, 2009). The CIT includes three steps: gathering critical incidents, rating their relevance for the task, and classifying incidents into requirements (Flanagan, 1954). To gather critical incidents, in-depths interviews were conducted. Subject matter experts shared their observations of situations central for interdisciplinary cooperation, in which a person made either a very positive or negative contribution to an interdisciplinary outcome. From those 
incidents, critical behaviours were derived and clustered into categories of interdisciplinarity requirements and corresponding competencies.

\section{Sample and Data Collection}

The sample consists of two data sets combined. For the first dataset, we contacted organizations in industry and academia and invited people with extensive experience in interdisciplinary work to be subject matter experts for this study. In the first data collection process, ten interviews with subject matter experts were conducted. All informants (six men, four women) were highly experienced in interdisciplinary projects. Seven of them worked in academia, while three of them worked in industrial settings. Informants had diverse disciplinary backgrounds (information technology, engineering, humanities).

The interviews were conducted in September 2014; five of them were face to face and the others took place via phone. All interviews were recorded and later transcribed. During each interview, informants were asked to describe two or more different critical incidents in interdisciplinary work. To do so, they recalled situations in which someone did either a very good or a very poor job in collaborating with a colleague from a different discipline (see online supplementary files for the interview protocols). Interdisciplinary work was defined as a collaboration of people from at least two different disciplinary backgrounds. We then asked about what led to the incidents, what the acting person did, as well as which behaviours would have been effective and ineffective in the respective situations. Each interview took about 30 minutes. From each critical incident, both positive and negative behaviours $(M=4.2$ behaviours per incident) were derived by the informant that clearly reflected interdisciplinary competency. In total, 101 critical behaviours were collected.

As a second data source, we used interviews using the CIT which were conducted to analyse requirements for holders of doctorates in academia and industry settings (for the interview protocol, see the online supplementary file). Invitations for participation were sent 
out via email to organizations that we knew to employ STEM graduates and via social networks. We interviewed a total of 16 people with $\mathrm{PhDs}$ in leadership positions. This study focused on STEM fields (science, technology, engineering, mathematics). Informants worked either in industry $(n=7)$ or academia $(n=9)$. Informants reported on a variety of requirements including interdisciplinarity. For inclusion, incidents had to refer to interdisciplinary competencies ${ }^{1}$. We extracted 24 behaviours from the eleven incidents extracted from this second data source.

Categorization and analysis are based on both data sets combined. Thereby, 125 positive and negative behaviours were included in the following qualitative analysis. A summary of incidents and behaviours is available as an online supplementary file.

\section{Results of Interview-based Data Collection}

The critical incidents and key situations reported by the interviewed subject matter experts built the data basis for deduced behaviours. First, the informants themselves were asked to point out particularly helpful or harmful behaviours. Second, the first author revisited the incidents and also extracted behaviours. Finally, during a following classification workshop, behaviours were deduced by workshop participants. All this information was combined for the classification process. In the following, we describe two incidents to give an example of incidents and the subsequent procedure. In the first situation, the informant assessed the behaviour of the acting person as positively related to interdisciplinary outcomes:

We wanted to launch a new chemical product and to do so there is quite an extensive workflow to follow. I sent [the acting person] to represent our department in the interdisciplinary team that would coordinate the product launch. The process to bring the final product on the market is described in great detail- 400 bullet points on the list. Then they discuss which department

\footnotetext{
${ }^{1}$ The critical incidents were rated in triplets by $n=89$ people using the Repertory Grid Technique.
} Here, raters had to compare the three incidents and describe similarities between two incidents. Whenever "interdisciplinarity" was mentioned, the incident was included in this study. 
does what, and what might be outsourced. [...]Members of that interdisciplinary team tried to pass the buck of unwanted tasks to one another. There is a lot of conflict potential. [The acting person] described well which possibilities and competencies our department has, but also what kind of expertise we don't have. Don't pass the buck, but don't monopolise either. After many hours, they organized the workflow and all tasks associated with it. (Incident 5, Informant 2)

Positive behaviours based on this were "explain own skills", "understand own limitations", "explain own limitations" and "take a fair share of tasks". The informant afterwards amended "step into other person's shoes". Negative behaviours would be "monopolise" and "pass the buck on unwanted tasks".

Some informants described situations in which a lack of interdisciplinary skills seriously hampered project success:

This happened in a transdisciplinary project and project partners were in different locations. Part of the project was to develop a lifeline for fire fighters which should be equipped with certain sensors like gas detectors. One project partner developed the lifeline, another one the sensors. After months of separate work, all partners met and also presented their prototypes. It was like a comedy: [a project partner] said "Well, now the lifeline is way too thin for the sensors". They didn't even communicate in the month apart. After this fiasco they decided that something needed to change. And it did. They talked more often; they showed openly what they were working on, not in an abstract matter, but hands on. (Incident 12, Informant 7)

This incident added behaviours such as "meet regularly", "openly show your work" and "talk 'hands on"'. In the same vein, all incidents were analysed regarding behaviours with positive or negative implications for interdisciplinary outcomes.

\section{Classification Workshop}

To condense the critical behaviours gathered in interviews, a classification workshop was held with six psychologists experienced in requirement analyses. Involving people with this background has been shown to improve categorization quality (Koch et al., 2009).

Transcripts of incidents and cards with corresponding behaviours were used as the starting point to sort and categorize. During the sorting procedure, the method of thinking aloud (Ericsson \& Simon, 1993) was employed to discuss which categories should be 
established and to define the differences between them. For each behaviour, participants discussed which requirement a person fulfils when engaging in this behaviour. Workshop participants developed names for categories based on included behaviours. When analysing behaviours based on critical incidents, several general competencies and behaviours commonly emerge. To ensure that specific requirements are the basis for the competency model, Flanagan (1954) suggests a relevance rating. Here, participants analysed the relevance of each category (“is this a typical requirement for interdisciplinary work?”) and its uniqueness for interdisciplinarity ("is this required for any kind of teamwork or is this unique for interdisciplinary collaborations?") and collectively decided whether or not a dimension should be kept.

\section{Results of the Classification Workshop}

As a result, four competencies were included in the model of interdisciplinary competencies (see Table 1). Initiative for exchange is defined as a proactive promotion of interdisciplinary collaboration by, for instance, making suggestions, proposing solutions, and initiating concrete discussions. In addition, the willingness to deal with additional expenses caused by interdisciplinarity is essential in this dimension. Target group-specific communication includes communicative behaviours, which are especially important in interdisciplinary settings, such as flexible adjustments in language for different audiences, "translating" between different disciplines, and patience in explaining. Knowledge integration refers to the cognitive process of combining and incorporating different disciplinary perspectives; it means an intellectual curiosity towards other disciplines, openness to others' arguments, and search for connections. Reflection and appreciation is a compound dimension involving reflecting on one's own disciplinary perspective and appreciation of other disciplines. Reflection on one's own disciplinary perspective includes behaviours such as realizing the limits of one's own discipline, upholding one's quality 
criteria, but also questioning one's premises. The appreciation of other disciplines includes valuing diversity and taking different approaches and methods seriously.

Insert Table 1 about here

The final rating of relevance during the workshop resulted in the exclusion of six dimensions from the final model due to their lacking uniqueness for interdisciplinarity; that is, those behaviours are assumed to have beneficial outcomes in any kind of collaboration and are not more strongly required in interdisciplinary than in disciplinary contexts. Those dimensions were cooperation skills (teamwork skills, conflict management), negotiation skills (arguing adequately), networking (introducing people, building and using professional networks), basic communication skills (active listening and formulating ideas concisely), management of meetings (writing meeting protocols, prioritizing), and professional expertise (being skilful in one's own discipline).

\section{Discussion of Study 1}

The proposed model of interdisciplinary competency consists of four dimensions: initiative for exchange, target group-specific communication, knowledge integration and reflection and appreciation (see Table 1). The compound dimension reflection and appreciation was developed as such because relevant behaviours in analysed incidents coincided. As many incidents involved behaviours from more than one competency dimension, we concluded that the model dimensions are not independent, but rather a composite that creates interdisciplinary competency.

This inductively derived model resonates well with the existing literature as it shows several similarities with known challenges of interdisciplinarity. Although initiative for interdisciplinary exchange does not have an immediate counterpart in previous research, we see a conceptual overlap with "personal commitment" from the extensive model by Brandstädter and Sonntag (2016). Target group-specific communication was mentioned in 
several interviews as being difficult (“...the entire topic of communicational barriers. That is especially true for certain wordings. Well, there are a lot of different problems in communication."-Informant 3) and reflects the core challenge of communication across disciplinary borders (Bromme, 2000), which can be explained by common ground theory (Clark, 1996). In the same vein, the importance of understanding different disciplinary perspectives and their view on a common research question or object of interest, that is, knowledge integration, has been highlighted before (Steinheider et al., 2009). It can also be compared to the elaboration of distributed knowledge, as considered by van Knippenberg et al. (2004). Reflection and appreciation were described as relevant personal prerequisites by our subject matter experts ("In some areas you cannot say that an employee earned the company a certain amount of money, because they were involved in a project. So appreciation is a constant topic for us. And I try to be creative in appreciating, looking at the entire process, see it as a holistic process"-Informant 6). A qualitative collection of experiences with interdisciplinary projects by Epstein (2005) also outlines appreciation as a personal competency for interdisciplinary work, while Lattuca et al. (2012) elaborate on the significance of reflecting on disciplinary perspectives for interdisciplinary endeavours. Nevertheless, our qualitative data showed no indication of a special role of meta-cognition, which has been shown before to be relevant for enabling individuals to quickly connect information from different disciplines (Bunderson, 2003).

Clearly, strengths and limitations of an inductive approach to developing the model have to be weighed. In our sample, informants from academic settings were overrepresented. This might have biased the results in a way that situations typical for research projects have been favoured over typical situations in industry settings. However, in the classification workshop, behaviours derived from interviews with informants in industry were earmarked. These behaviours did not cluster but were spread evenly over all dimensions. Hence, there is 
no reason to believe that the sample composition biased the results. Clearly, the classification of incidents and behaviours into competency requirements can be a rather subjective procedure. However, close adherence to qualitative data keeps this theory building well justified (Eisenhardt \& Graebner, 2007). In our case, the classification of behaviours into competency dimensions was done by a single workshop group. Although we implemented recommendations by Koch et al. (2009) in the classification process (e.g., method of thinking aloud, experienced participants) to increase objectivity and reliability, we cannot guarantee that a second workshop group would have arrived at a completely identical competency model. The chosen approach is clearly limited as it does not allow studying inter-rater reliability. Nevertheless, the results' credibility is increased by the fact that the proposed competency dimensions have been discussed in the literature before, although not with this specific composition and context. Furthermore, the subsequent studies will test the validity of the model results to improve upon limitations of the classification approach.

In sum, this qualitative study provides insight into competency requirements in interdisciplinary collaborations. The developed model is parsimonious, unique for interdisciplinary collaborations, and integrates various challenges linked to interdisciplinarity. As a result, this study provides a model for interdisciplinary competencies that can be deductively tested.

\section{Study 2: First Quantitative Test of the Competency Model}

Our goal for the second study was threefold. First, we wanted to test the conceptual dimensions of the model in a quantitative study with a larger sample to ensure that the model dimensions actually mirror the appropriate scope of individual experiences in interdisciplinary collaborations. Second, we wanted to develop a scale to address the experiences of employees in interdisciplinary collaborations focusing on self-reported interdisciplinary competencies. Third, as a first validation of the model, we analysed convergent validity with regard to motivation for interdisciplinary work and considered the 
influence of experience and significance of interdisciplinarity for the job tasks on selfreported interdisciplinary competencies (i.e., initiative for exchange, target group-specific communication, knowledge integration and reflection and appreciation).

For a first test of convergent validity, we analysed the relation between the connected yet independent variables of interest in interdisciplinary work and competencies. Motivation in general, and interest in particular, is beneficial for competency development (Krapp, 2002). Additionally, there is evidence that perceived proficiency generates greater interest in a field or activity (Bandura \& Schunk, 1981). Analyses of convergent validity should demonstrate this positive relationship between interdisciplinary competencies and interest. H1: Interdisciplinary competencies are positively related to interest in interdisciplinary work.

Furthermore, based on theories of competency development (Ley, Lindstaedt, \& Albert, 2005), we consider workplace experience with interdisciplinarity relevant. Longlasting experience in interdisciplinary teamwork should be related to more incidents for learning and competency development and as such lead to an increase in interdisciplinary competencies. In the same vein, van Knippenberg et al. (2004) emphasize that collaborators need time to develop competencies to elaborate divergent perspectives. Cummings and Kiesler (2008) have shown that previous experience with a particular colleague improves engagement in interdisciplinary projects with this person and as a consequence project outcomes. Similarly, we suggest that previous experience with interdisciplinary projects would enhance relevant competencies. At the same time, people with interdisciplinary competencies might be more strongly attracted to jobs with requirements for a high degree of interdisciplinary collaboration. In addition, we propose the significance of interdisciplinarity for the current job to be relevant. The more the job depends on interdisciplinary collaboration, the more resources should be invested into making interdisciplinary 
collaboration work. Consequently, in settings of high dependency on interdisciplinarity, more opportunities for competency development emerge, leading to higher competency levels. H2: Experience in interdisciplinary work is positively related to interdisciplinary competencies.

H3: Significance of interdisciplinarity for the job is positively related to interdisciplinary competencies.

\section{Method}

To test the proposed model of interdisciplinary competencies and our hypotheses, we conducted an online survey among employees with experience in interdisciplinary work.

\section{Item Development}

Based on the previously developed model of interdisciplinary competencies, the authors formulated items for each dimension. The wording focused on competencies and thus included phrases such as "I can easily" or "I'm good at". We developed items for each model dimension: initiative for exchange ("It is easy for me to take the initiative in an interdisciplinary meeting"), target group-specific communication (“In interdisciplinary teams, it is difficult for me to avoid unnecessary technical terms"), knowledge integration (“In interdisciplinary work, I am good at connecting and integrating knowledge from different disciplines") and reflection and appreciation ("I can very precisely name the problems my discipline deals with and where differences from other disciplines lie").

To check face validity, items were randomized and allocated to the model dimensions by four senior scientists and student assistants familiar with the model of interdisciplinary competency. Mismatched items were either revised to better represent only one dimension or excluded. The item development process resulted in a pool of 66 items for four model dimensions. Items were rated on a 6-point scale. Regarding convergent validity, we drafted four items on interest in interdisciplinary work; that is; whether one enjoys working in an interdisciplinary team ("The possibility to work interdisciplinarily contributes to my work 
satisfaction", "I want to do more interdisciplinary work", "The possibility to do interdisciplinary work inspires me", "It tempts me to work with people from other disciplines that have a completely different approach to things than I have"). Experience in interdisciplinary work was reported in years. Significance of interdisciplinarity for the job was measured with a single item ("How significant is interdisciplinary cooperation for your job?") on a 5-point rating scale ( $1=$ unimportant; 5 = very important $)$.

\section{Sample}

To recruit participants for the online questionnaire study, employees of organizations with an interdisciplinary focus and researchers with a history of interdisciplinary work (based on website information of employing organizations and research funding agencies) were invited via email to participate in the survey. We looked for organizations working in sustainability, biomedicine, bioengineering, and human-machine-interaction, because these fields are known for their interdisciplinarity. The recruiting process resulted in a convenience sample of 315 employees (55.3\% women) who work interdisciplinarily. Participants were between 22 and 68 years old $(M=36.81 ; S D=9.33)$ and had on average eight years of experience in interdisciplinary work $(M=7.92$ years; $S D=7.17)$. Most participants $(84.5 \%)$ currently worked in academia and $98.4 \%$ of participants had completed further education and thus had been socialized in an academic discipline (59.9\% humanities and social sciences, $21.5 \%$ in engineering, $12.7 \%$ in natural sciences, $5.9 \%$ life sciences). Most participants (75.8\%) worked at least weekly with people from other disciplines (38.5\% daily interdisciplinary work). A subsample of 202 people (64.1\%) completed the survey on a second occasion, with a retest interval of approximately two weeks.

\section{Analytical Approach}

At the beginning, items were selected based on descriptive item analysis, factorial approaches and considerations of item content to reduce the overall number of items. Based on the results of the qualitative study, in which behaviours associated with different 
competency dimensions occurred in similar situations, we did not expect statistical independence of model dimensions. We employed exploratory structural equation modelling (ESEM; Asparouhov \& Muthén, 2009), which combines features of exploratory factor analysis and confirmatory factor analysis (CFA). ESEM enables the testing of models with item cross-loadings and should fit the hypothesized structure better than CFA models. CFA is based on independent cluster models (ICM-CFA) and thus poses overly strict assumptions regarding zero cross-loadings. This assumption may lead to a poor model fit for many psychological constructs, which often have slightly correlated factor structures, such as the Big Five personality factor structure (Marsh et al., 2009).

To obtain information on measurement generalizability, we conducted tests of measurement invariance over the retest interval. Using the data from the subsample of 202 people who took the survey a second time, we applied the taxonomy for longitudinal measurement invariance by Marsh et al. (2009). It implies a comparison of increasingly restricted models between time points, from weak to complete measurement invariance.

Finally, to test our hypotheses, interest in interdisciplinary work was correlated with the competency dimensions as an indicator for convergent validity (H1). Also, years of interdisciplinary experience $(\mathrm{H} 2)$ and significance of interdisciplinarity for the current job (H3) were linked to the model dimensions in a regression model.

\section{Results}

The following analyses are based on a sample of 315 people from the first part of the study. Analyses based on the subsample of 202 people who took part in a repeated measurement are labelled accordingly.

As a first step, we combined different analytical methods to reduce the number of items yielding three to four items per dimension. Based on descriptive item analysis, only a few items were excluded: four items due to low item difficulty $\left(\mathrm{P}_{\mathrm{i}}<0.85\right)$ and one item due to little variance. Both low item difficulty and little variance confine the information that can 
be gathered from an item: if nearly all participants fully agree with an item, little information about the interdisciplinary competencies of an individual can be inferred. The remaining 61 items for the competency dimensions as well as the four interest items were screened in an iterative process: factorial analyses with five factors (that is, four for the hypothesized model dimensions and an additional interest factor) were the starting point (see online supplementary table). We then removed items with inconclusive factor loadings and very high cross-loadings step by step. In addition to repeated statistical analyses with a decreasing item set, we considered whether the remaining items covered the content of the dimensions appropriately. This process yielded an item set of 13 competency items (Table 2).

Insert Table 2 about here

The ESEM model based on these 13 items as well as four items on interest in interdisciplinary work and a 5-factor structure reveals that the factor loadings do not fully represent the hypothesized pattern. Items intended to represent the dimension reflection and appreciation of the qualitative model load on two separate factors. Some items form a pure "reflection" factor. The two items measuring the appreciation of interdisciplinary work load on the same factor as the interest items and thus create a common factor of interest and appreciation. This pattern was similarly observed in all previous analyses we did. As a consequence, we decided to drop this factor; thus, all further analyses are based on the four factor version only, including competency factors but excluding the "interest and appreciation" factor (see Table 2).

The ICM-CFA model with the remaining 13 items fits the proposed data structure quite well $\left(\chi^{2}=91.72 ; d f=59 ; \mathrm{CFI}=.937 ; \mathrm{TLI}=.956 ; \mathrm{RMSEA}=.042 ; \mathrm{SRMR}=.043 ;\right.$ see Table 2). However, correlations of the latent factors are relatively large, with $r$ s between .37 and $.72($ median $=.52)$. In comparison, the corresponding ESEM model with 13 items fits the 
data better $\left(\chi^{2}=39.82 ; d f=32 ; \mathrm{CFI}=.992 ; \mathrm{TLI}=.981 ; \mathrm{RMSEA}=.028 ; \mathrm{SRMR}=.021\right)$. The factor correlations of the latent ESEM factors based on standard geomin rotation are lower, with a median $r$ of .37 ( $r$ s between .26 and .52$)$.

This result indicates that the less restrictive ESEM model is more suitable for the underlying data structure with slightly correlated latent factors. Thus, we built our further analyses on the geomin-rotated ESEM model (see Table 3).

Insert Table 3 about here

We tested measurement invariance over the two-week retest interval. Results suggest strong, although not strict, measurement invariance over time $\left(\chi^{2}=289.53 ; d f=213 ; \mathrm{CFI}=\right.$ $.969 ; \mathrm{TLI}=.952 ; \mathrm{RMSEA}=.034 ;$ SRMR $=.062$ ). Therefore, factor loadings, uniquenesses, factor variance-covariances and intercepts can be compared at both time points. Whenever the more parsimonious model (i.e., containing more constraints) was compared with the less parsimonious model, fit indices revealed only slight deteriorations in fit $(\triangle \mathrm{RMSEA}<.015$; $\Delta \mathrm{CFI}$ and $\Delta \mathrm{TLI}<.10)$. In many cases, adding constraints actually improved fit according to indices that control for parsimony (RMSEA, TLI). The short-term retest correlations based on latent factors range from .70 to .92 and thus speak in favour of short-term stability.

As ESEM requires all factors to be simultaneously related or unrelated to external variables, we converted the ESEM model into a CFA model for further analyses according to the ESEM-within-CFA approach (Morin, Marsh, \& Nagengast, 2013). To test convergent validity as described in $\mathrm{H} 1$, we correlated a latent variable of interest in interdisciplinarity and the latent factors of interdisciplinary competencies. Correlation coefficients are significant and vary for the competency dimensions initiative for exchange (.23), target group-specific communication (.17), knowledge integration (.40) and reflection (.11). Table 4 shows correlations between all constructs for Study 2. 
Insert Table 4 about here

To test Hypotheses 2 and 3, we estimated the influence of experience in interdisciplinary work and the significance of interdisciplinary cooperation for the current job on self-reported competencies using path analysis, as shown in Figure 1. Each year of experience in interdisciplinary work is associated with slight increases in initiative for exchange, knowledge integration and reflection (H2). The significance of interdisciplinary cooperation for the job is positively related to initiative for exchange, target group-specific communication and knowledge integration (H3). We also included interest in the model depicted in Figure 1. Please note, however, that in the regression model the path between interest and target group-specific communication is not statistically significant.

Insert Figure 1 about here

\section{Discussion of Study 2}

We applied the model of interdisciplinary competencies in a survey among employees with experience in interdisciplinary work to test its dimensions. We were able to replicate the findings of the previous qualitative study, in which the dimensions initiative for exchange, target group-specific communication, and knowledge integration were extracted. However, the quantitative data show a different pattern than expected regarding reflection and appreciation. In the qualitative interviews, incidents with behaviours linked to those dimensions included both dimensions, thus leading us to believe them to be a compound characteristic of interdisciplinary competencies. As the quantitative data did not support this hypothesis, we focused on the competency of reflection, representing awareness of one's own disciplinary perspectives. The other part of the compound competency, appreciation, merged into a common factor with interest. Taking item content overlap into account, we understood that appreciation and interest share a common motivational underpinning. We concluded that 
appreciation of other disciplines is an attitudinal prerequisite for interdisciplinary work that might ease collaboration. This motivational perspective on appreciation fits less well with our understanding of competencies as capabilities (Boyatzis, 2008). Consequently, we decided to remove appreciation from the compound dimension and to focus on reflection instead.

Next, we tested our items designed to measure interdisciplinary competencies for measurement invariance. Strong measurement invariance was found for the repeated measure. These analyses indicated that item intercepts as well as factor loadings are invariant over time and latent means can appropriately be compared. Please note that we, in fact, found substantial retest stability over a short-term interval.

For the purpose of construct validation, we considered the association between competencies and interest. Interest can be seen as a prerequisite for engaging in interdisciplinary work and developing interdisciplinary competencies. We observed low to moderate correlations with initiative for exchange, knowledge integration and reflection. However, there was no significant relationship between target group-specific communication and interest, suggesting that an interest in engaging in interdisciplinary work can be independent from required communication competencies.

Path analysis showed that experience in interdisciplinary work and significance of interdisciplinarity for the job had specific effects on the model dimensions. Each year of experience in interdisciplinary work increases a person's initiative in interdisciplinary settings and their reflection on their own disciplinary perspective. This result provides a first impression of competency development in interdisciplinary work environments on the job. The main predictor of self-reported interdisciplinary competencies was the significance of interdisciplinary cooperation for the job. The more relevant the collaboration with other disciplines was to fulfilling job requirements and tasks, the higher the self-reported 
competencies. However, high relevance was not associated with reflection, a competency dimension that is less task-oriented than the others.

This study was a first test of the model of interdisciplinary competencies. As such, it also has certain limitations. Employees working in academia were overrepresented in our sample. We do assume that interdisciplinary collaborations are associated with certain requirements - which stem from the collaboration of people with different disciplinary backgrounds and perspectives. It is the multitude of perspectives that makes interdisciplinary work complicated, and we assume that this effect is independent from the particular sector or industry. Nevertheless, in academia, disciplinary identities might be more apparent, as most academic organizations are clearly organized according to disciplinarity, while this is not necessarily the case for organizations outside of academia. Thus, this study's implications might be limited to the academic work environment and clearly defined disciplines. A second limitation concerns the use of a single item measuring the significance of interdisciplinarity for the work task. All items are prone to potential misunderstandings based on wording; however, with single items this cannot be remedied by averaging.

We could clearly confirm the proposed model of interdisciplinary competencies in a sample of experienced practitioners. As a consequence, the findings support the qualitative approach featured in Study 1 and compensate some limitations of the previous study. In addition, the study revealed experience and significance of interdisciplinary cooperation as relevant predictors of self-reported interdisciplinary competencies.

\section{Study 3: Further Model Validation}

In the third study, we continued to validate the model. One goal was to replicate the findings of Study 2 and show that the developed model generalized in a more diverse sample. The second goal was to study the relationship between interdisciplinary competencies and related concepts for convergent validation. The third goal was to show that interdisciplinary 
competencies are predictive for interdisciplinary team outcomes above and beyond general teamwork competencies.

In our samples in both Study 1 and Study 2, employees working in academia were overrepresented. Although we assume that the mechanisms of interdisciplinary work are similar between industry and academia, we wanted to show that the interdisciplinary competency model developed works well in teams outside of academia, too.

To further validate the model, the relationship between interdisciplinary competencies and other constructs should be studied. We expect interdisciplinary competencies to be positively related to a general preference for teamwork and self-efficacy for teamwork, as well as interest in interdisciplinary work (a link we have seen in Study 2). Interest, selfefficacy beliefs and competency development are closely linked (Bandura, 1994): positive experiences with interdisciplinarity strengthen both interest and self-efficacy beliefs, which in turn foster competency development. Interest, self-efficacy, and a preference for teamwork are motivational prerequisites for the effort of developing interdisciplinary competencies and to grapple intensely with other disciplines. With regard to the organizational circumstances of interdisciplinary work, we assume that managerial support for interdisciplinary work and high task interdependence help create surroundings in which interdisciplinary competencies can be developed. Supportive managers are aware of the requirements of interdisciplinary work and are more likely to provide the necessary resources for interdisciplinary interactions such as more time and the opportunity to reflect on the challenges of interdisciplinary work which are beneficial for the development of interdisciplinary competencies. High task interdependence forces peers to work closely together to accomplish their work tasks. Here we assume an increased motivation to make interdisciplinarity work by developing interdisciplinary competencies. 
HIa: Interdisciplinary competencies are positively related to interest in interdisciplinary work, preference for teamwork and self-efficacy.

H1b: Interdisciplinary competencies are positively related to managerial support for interdisciplinary work and task interdependence.

H2: Interdisciplinary competencies predict outcomes of interdisciplinary teamwork above and beyond general teamwork competencies.

\section{Method}

Study 3 was an online study with a sample of dyads of employees who work interdisciplinarily. To improve generalizability of the developed model, we aimed at including more non-academic participants in the sample.

\section{Sample}

This sample has a dyadic structure. We recruited $N=448$ participants (57.6\% women) with experience in interdisciplinary work as target persons and had them invite a colleague with a different disciplinary background for a peer rating. This resulted in a sample of $n=$ 153 dyads. To recruit target persons with non-academic backgrounds, we contacted interdisciplinary health care clinics, centres for social paediatrics, theatres, museums, and environmental agencies. Target persons were on average 41.96 years old $(S D=11.46$; peers: $M=38.70 ; S D=10.55)$ and $85.9 \%$ had a university degree $(7.6 \%$ humanities, $40.1 \%$ economics and social sciences, $10.8 \%$ natural sciences, $18.6 \%$ medicine and health, $10.6 \%$ engineering). Most participants (91.5\%) without a degree had completed an apprenticeship (e.g., nursing, physical therapist). Most common occupations among target persons were social workers $(n=55)$, physicians $(n=53)$, psychologists $(n=44)$, nurses $(n=12)$, theatre dramatic advisers $(n=8)$, and museum curators $(n=7)$. Only $28.8 \%$ of target persons worked in academia. Among the peers (74.3\% women), $80.4 \%$ had a university degree $(4.9 \%$ 
humanities, $39.8 \%$ economics and social sciences, $7.3 \%$ natural sciences, $27.6 \%$ medicine and health, $12.2 \%$ engineering).

The relationship between the target person and the corresponding peer was characterized as being colleagues by $60.8 \%$ and project partners by $18.3 \%$. In $9.8 \%$ of cases, subordinates answered the peer survey. In $2.0 \%$ of cases, the peer was the superior of the target person. We tested whether target persons who obtained a peer report and those who did not differed from each other regarding demographics and self-reported interdisciplinary competencies. Target persons with a peer report had significantly more often received a university degree $\left(\chi^{2}(1)=10.66 ; p<.001\right)$ and rated their knowledge integration competency higher than target persons who did not obtain a peer report $(t(445)=2.11 ; p<.05)$.

\section{Instruments}

Instruments for target persons and peers differed. Target persons were given a more extensive survey. All items were rated on a 6-point rating scale.

Target person's questionnaire. Interdisciplinary competencies were measured using the 13 item scale developed in Study 2 (see Table 2). For general teamwork competencies, the Teamwork Competency Instrument by Halfhill and Nielsen (2007) was used. We included the subscales conflict resolution, collaborative problem solving, communication, goal setting and performance management, planning and task coordination, and meeting management skills with three items each. An example would be "I help establish specific, challenging, and accepted team goals" (subscale goal setting and performance management).

In addition, we included two groups of convergent measures: (a) motivational attitudes toward teamwork (interest, self-efficacy, and preference for teamwork) and (b) organizational aspects of interdisciplinary work. Interest in interdisciplinary work was measured with the same four items as in Study 2 (e.g., "The possibility to do interdisciplinary work inspires me"). Self-efficacy for teamwork was measured with three items from the scale 
by Eby and Dobbins (1997), e.g., "I can work very effectively in a group setting”. We included three items from the subscale Preference for Teamwork from the Workgroups Characteristics Measure (Campion, Medsker, \& Higgs, 1993) in the original wording (e.g., "I generally prefer to work as part of a team”). Regarding organizational aspects, we adapted items from the Workgroups Characteristics Measure (Campion et al., 1993) to fit to interdisciplinary work (changes are marked in italics): managerial support for interdisciplinary work (e.g., "Higher management in my organization supports the concept of interdisciplinary teams") and task interdependence (e.g., "I cannot accomplish my task without information or materials from other team members from a different discipline”) which were measured by three items each.

As outcomes we included measures of team effectiveness and satisfaction with the team and adapted them to better fit to interdisciplinary teamwork. Team effectiveness was measured by four items originally from Maynard, Mathieu, Rapp, and Gilson (2012). A sample item is "How effective was your team in making use of the skills of the different team members and disciplines?". Here, we added "and disciplines". Team satisfaction was measured by three items from Hertel, Konradt, and Orlikowski (2004), e.g., "I am satisfied with the team climate among the interdisciplinary members of the team".

Peer questionnaire. The peer questionnaire only included demographics and outcome measures: four items of Team Effectiveness (Maynard et al., 2012) and three items for Team Satisfaction (Hertel et al., 2004).

\section{Analytical Approach}

First, to replicate the factor structure found in Study 2, we used confirmatory factor analysis. Second, we tested convergent validity according to Hypotheses $1 \mathrm{a}$ and $1 \mathrm{~b}$ using structural equation modelling with latent variables. Third, we compared interdisciplinary competencies with general team competencies in predicting team outcomes. As the sample 
size of the peer sample is relatively small, latent variables were transformed into manifest factor scores which were used for the regression models. In small samples, complex models with latent variables cannot be estimated, but using factor scores makes this possible (Devlieger \& Rosseel, 2017). This leads, however, to the model being saturated; thus, the fit indices cannot be interpreted.

\section{Results}

We applied the ESEM and CFA analyses from the second study to the new sample to replicate the findings. For these analyses, we used the larger sample of all target persons $(N=$ 447).We were able to fully replicate the results with a well-fitting CFA model $\left(\chi^{2}=93.68 ; d f\right.$ $=59 ; \mathrm{CFI}=.973 ; \mathrm{TLI}=.965 ; \mathrm{RMSEA}=.036 ; \mathrm{SRMR}=.041)$, although it did not fit as well as the replicated ESEM model $\left(\chi^{2}=30.37 ; d f=32 ; \mathrm{CFI}=1.000 ; \mathrm{TLI}=1.003 ; \mathrm{RMSEA}=\right.$ $.000 ; \mathrm{SRMR}=.016)$. Once again, latent factor correlations were smaller in the ESEM ( $r \mathrm{~s}$ from .20 to .70 ; median $r=.38$ ) than in the CFA model ( $r$ s between .26 and .74 ; median $r=$ .41). To replicate the ESEM model estimated in Study 2, we applied the ESEM-within-CFA approach (Morin et al., 2013).

To test Hypothesis 1a, we correlated latent factors of interdisciplinary competencies and interest, preference for teamwork, and self-efficacy for teamwork. The model fit well $\left(\chi^{2}\right.$ $=278.57 ; d f=161 ; \mathrm{CFI}=.96 ; \mathrm{TLI}=.95 ; \mathrm{RMSEA}=.04 ; \mathrm{SRMR}=.04)$. We found significant medium to high correlations between the interdisciplinary competencies initiative for exchange, target group-specific communication, and knowledge integration with interest, preference for teamwork and teamwork self-efficacy (see Table 5). For reflection, however, only the correlation with self-efficacy for teamwork was significant $(r=.36 ; p<.001)$.

Likewise, we tested the correlations between the interdisciplinary competency dimensions (latent variables) and the environmental variables of managerial support and task interdependence (Hypothesis $1 \mathrm{~b}$, see Table 5). The model fit well $\left(\chi^{2}=188.81 ; d f=110 ; \mathrm{CFI}\right.$ 
$=.97 ; \mathrm{TLI}=.95 ; \mathrm{RMSEA}=.04 ; \mathrm{SRMR}=.04)$. Managerial support for interdisciplinarity was significantly associated with target group-specific communication $(r=.23 ; p<.001)$ and knowledge integration $(r=.19 ; p<.01)$. Task interdependence is significantly correlated with initiative for exchange $(r=.33 ; p<.01)$, target group-specific communication $(r=.15$; $p<.05)$, knowledge integration $(r=.27 ; p<.001)$, and reflection $(r=.18 ; p<.01)$. A complete correlation table is available as an online supplement.

\section{Insert Table 5 about here}

The following analyses were carried out in the combined sample of target persons and peers $(n=153)$. We calculated factor scores using CFA modelling for each construct (interdisciplinary competencies, team competencies, outcomes). All fit indices met the criteria of a good fitting model. In a first step, we modelled the general team competencies as predictors for team effectiveness and team satisfaction (self- and peer-report). The selfreported team competencies (conflict resolution, collaboration, communication, goal setting, planning, meeting management) together explained $13.9 \%$ of the variance $\left(R^{2}\right)$ of selfreported team effectiveness $(p<.001)$ and $7.2 \%$ of the peer-reported team effectiveness $(p=$ .08; see Table 6). With regard to team satisfaction, general team competencies accounted for $7 \%$ of self-reported team satisfaction $(p<.01)$ and $8.4 \%$ of the team satisfaction of peers $(p=$ .06). Self- and peer-reported outcomes were positively correlated with team effectiveness ( $r=$ $.23 ; p<.05)$ and team satisfaction $(r=.33 ; p<.001)$. In a second step, we included interdisciplinary competencies as additional predictors. The inclusion of interdisciplinary competencies increased the $R^{2}$ of team effectiveness to .21 ( $p<.001$; self-report) and .14 ( $p<$ .01 ; peer-report), respectively. The explained variance in satisfaction with the team increased to $17.0 \%(p<.001$; self-report) and $12.3 \%$ ( $p<.05$; peer-report). Hence, interdisciplinary competencies predicted team outcomes above and beyond general team competencies. 
Insert Table 6 about here

\section{Discussion of Study 3}

In Study 3, we applied the model developed in the previous studies in a new sample and replicated the statistical model of interdisciplinary competency dimensions initiative for exchange, target group-specific communication, knowledge integration, and reflection. In addition, we were able to show convergent validity. Interdisciplinary competencies were related to the following constructs: interest in interdisciplinary work, teamwork self-efficacy, and a general preference for teamwork. These three constructs can be understood as motivational and attitudinal prerequisites of successful interdisciplinary collaborations (Bandura, 1994). In particular, it is assumed that these motivational constructs are an indicator for the effort one invests in developing interdisciplinary competencies. Furthermore, interdisciplinary competencies were related to organizational aspects of interdisciplinary work. There were small to moderate correlations between task interdependence and all four competency dimensions: The more a person depends in her or his own work on information from interdisciplinary colleagues, the higher this person rates her or his interdisciplinary competencies. This indicates that competencies might develop as a necessity to cope with interdisciplinary requirements. Managerial support was associated with higher self-reports of target group-specific communication and knowledge integration.

An important goal we pursued with Study 3 was to demonstrate the generalizability of the model of interdisciplinary competencies. Most importantly, we wanted to demonstrate that interdisciplinary competencies are different from general teamwork competencies. Interdisciplinary work most often is teamwork; however, it is a very particular kind of teamwork with unique challenges and requirements. Hence, we argue that successful interdisciplinary work requires (additional) competencies different from general teamwork competencies. General teamwork competencies as a group predicted self-reported team 
effectiveness and the team satisfaction of the target person albeit only communication skills were a significant single predictor. They were not, however, able to explain a colleague's team satisfaction or team effectiveness rated by peers. Including interdisciplinary competencies in the prediction model improved explained variance. This change was significant for the self-report measures. Although initiative for exchange and reflection were not significant as single predictors, the combined interdisciplinary competencies explained team effectiveness and satisfaction with the team above and beyond general team competencies. Our results suggest knowledge integration and target-group specific communication to be core competencies for interdisciplinarity. The capability to successfully interact and integrate between disciplines has shown to be associated with self-rated team satisfaction and self- and peer-rated team effectiveness. The amount of variance explained in the outcomes by the predictors was, however, rather low.

Team satisfaction can be explained by various aspects from team culture to traits of the target person and colleagues. Participants worked in different settings of interdisciplinarity. We sampled dyads; however, some of the dyads were part of a bigger team. Here, team satisfaction is most likely explained by traits and competencies of more than one colleague, which could explain the lacking effects of competencies for the colleague's team satisfaction. Higher associations between self-reported competencies and self-reported outcomes can be explained by same source bias and are not surprising (Lindell \& Whitney, 2001). It should also be noted that relatively low correlations among the outcomes in self- and peer-reports correspond with meta-analytical findings of self- and other-reports (Heidemeier \& Moser, 2009).

Another important study aim was to tackle generalizability by targeting a sample outside of academia. Many participants worked in the health sector and provided care in interdisciplinary teams. Another group of participants came from the cultural sector and 
worked interdisciplinarily in theatres and museums. Whenever different disciplines come together to work together, interdisciplinary competencies are required. The converging evidence in support of the model from the previous study, in which academics were overrepresented, shows that the requirements are comparable for different industries or sectors.

A clear strength of Study 3 is the use of peer reports in addition to the target persons' self-reports. This avoids the pitfalls of common method variance and improves the credibility of the results. Nevertheless, we need to acknowledge that only about a third of the sampled target persons obtained a peer report. From responses of reminders sent out to target persons, we learned that most target persons were willing to ask a colleague but not all of them were successful. We found that those who received a peer-report self-rated their knowledge integration competencies higher than those who did not obtain a peer-report. However, there were no group differences with regard to other competency or outcome ratings, which would point to selection effects that might have affected our overall result patterns.

\section{General Discussion}

Interdisciplinary work is promising regarding possible innovations, yet is experienced as being particularly demanding. We argue that competencies of individuals in interdisciplinary teams help to overcome hurdles and thus enable the utilization of interdisciplinary potential. We set out to explore what kind of competencies support successful interdisciplinary work.

Our research is based on a mixed-methods approach. We combined a study of qualitative data and inductive model development with two subsequent deductive tests. Our findings suggest that interdisciplinary competencies can be described by four related model dimensions: initiative for exchange, target group-specific communication, knowledge integration and reflection. These dimensions resonate well with existing literature on singular challenges in interdisciplinary work (Bromme, 2000; Lattuca et al., 2012; Steinheider et al., 
2009). The model combines these dimensions to cover a broader scope of competencies in interdisciplinary work. Yet, our inductive study also enabled the review of competencies for their specificity for interdisciplinary endeavours and thus to advance and condense the model of Brandstädter and Sonntag (2016). Moreover, the first quantitative study of the model in a sample of interdisciplinary practitioners revealed both experience in interdisciplinary work and the significance of interdisciplinarity for the current job as relevant predictors for selfreported competencies. These results provide first clues to competency development. The second quantitative study complemented the results by showing convergent validity with respect to teamwork self-efficacy, preference for teamwork, task interdependence, and managerial support, as well as incremental validity with respect to general teamwork competencies in predicting team outcomes.

\section{Theoretical and Practical Implications}

Disciplinary perspectives are developed through socialization within a certain academic or occupational field. Disciplinary perspectives are a deep-level characteristic that shapes different aspects of everyday work. This characteristic is part of what makes interdisciplinary work difficult to do (Epstein, 2005). As a consequence, interdisciplinary work differs from general teamwork with regard to requirements, demands, and competencies. The model presented here helps to understand these differences and integrates previous research on challenges of interdisciplinary work such as communication across disciplinary borders and knowledge integration (Bromme, 2000; Steinheider et al., 2009).

Previous research has focused on the team level or organizational means of supporting disciplinary or functionally diverse teams. Our research complements this perspective by zooming into individual competencies in the interdisciplinary teamwork context. The results

indicate that a single individual with his or her competencies can help make teams successful. From our point of view, a team is not an abstract construct that can be studied independently from its members; rather, individual competencies and characteristics are the basis for team 
outcomes. These individual competencies can then be transferred from one collaboration to another, which makes them particularly relevant for staffing decisions.

In addition, it is worth discussing what makes a discipline. Traditional definitions of interdisciplinarity (Newell, 2001; Repko et al., 2014; Szostak, 2002) build upon the history of science and how academic disciplines evolved. Nevertheless, socialization into a "discipline" also happens outside of the ivory tower of academia. Interdisciplinarity has been a trend in science in the past decades; in industrial settings, however, teams of experts from different fields have been common even longer. As we aimed at sampling fewer academics for Study 3 , the question arose as to whether disciplinary perspectives are tied to university degrees or might be developed in non-academic occupations such as midwifery as well. This issue is not addressed in definitions of interdisciplinarity, and we decided to include occupations with a strong sense of disciplinarity and relatively clear understandings of responsibilities, as can be observed in health occupations (nursing, midwifery, physiotherapists) or creative occupations (stage designer, conductor). The present model of interdisciplinary competencies can be of practical use in personnel selection and development. The model can help to develop specific behavioural measures in addition to the questionnaire instrument introduced here. These specific instruments can be used for purposes of personnel selection (e.g., in an assessment centre), for self-reflection, as well as for evaluation of interdisciplinary collaborations and personnel development. Moreover, the model of interdisciplinary competencies can provide a basis for specific interventions to foster interdisciplinary collaboration.

\section{Strengths, Limitations and Future Research}

The reported studies contribute to the theoretical understanding of how individuals can achieve success in interdisciplinary project teams. The model enables the analysis of an individual's competencies as a driving mechanism for interdisciplinary cooperation.

As with any research, strengths and weaknesses have to be weighed. A clear strength is the mixed-method approach. As qualitative theory-building and quantitative theory-testing 
complement each other (Eisenhardt \& Graebner, 2007), we decided to utilize both research strategies to strengthen the case for our model. The consistency of results across different research methodologies indeed accomplishes that objective. Nevertheless, a limitation of the quantitative studies concerns the self-report data for competencies. The construct of competencies calls for performance data. With regard to outcome measures, we implemented a peer-report in the third study to avoid common method variance. We propose a new competency model which is parsimonious and specific for interdisciplinary collaborations. As such, it advances previous work and identifies relevant competency dimensions. The clear focus on competencies is also apparent in the self-report measure we developed.

Interdisciplinary collaborations are manifold: they can be project based or ongoing, they can happen within one organizational unit or across organizations, and the disciplines involved can be closely related or rather distant. This multitude of manifestations of interdisciplinarity reflects how common interdisciplinary work has become, but also reflects very different working conditions and arrangements. Interdisciplinary competencies are relevant in all of these varied contexts; nevertheless, it is difficult to compare these collaborations. Our studies tried to represent this diversity to develop a model of interdisciplinary competencies that is not limited to a certain mode of collaboration or industry. However, in two of our studies, research teams were overrepresented. Fortunately, in Study 3, we overcame this potential bias. But it has to be acknowledged that interdisciplinary teams differ in many respects (e.g., hierarchy, distance of disciplines, goals, level of integration) and that controlling for these differences was not in focus in our designs.

Future research should overcome the method-specific limitation by utilizing other research measures with a focus on performance, such as behavioural data from the field or lab. The self-report of competencies we considered here may differ from measures of interdisciplinary competencies obtained from reports of colleagues or supervisors or from 
behavioural observations. Researchers should include performance measures and examine the relations between them and self-reported interdisciplinary competencies. Our study suggests that experiences in interdisciplinary work increase certain interdisciplinary competencies. Future research should address the mechanisms and conditions for competency development on the job, as this understanding is crucial for future applications and possible interventions. In addition, one limitation is the mostly cross-sectional nature of our data, which does not allow determining causality; thus, relevant questions regarding development mechanisms remain unanswered.

\section{Concluding Remarks}

Interdisciplinarity holds the potential for innovation and progress in many areas of science and everyday life. Part of this potential is lost due to difficulties in interdisciplinary collaboration. The theoretical understanding of individuals' competencies as a basis for successful collaborations requires a competency model. There is a clear necessity to better understand mechanisms of competency development and competencies' relevance for team success. This study hopefully serves as a first step in this important endeavour. 


\section{References}

Asparouhov, T., \& Muthén, B. (2009). Exploratory structural equation modeling. Structural Equation Modeling, 16, 397-438. doi:10.1080/10705510903008204

Bandura, A. (1994). Self-efficacy. In V. S. Ramachaudran (Ed.), Encyclopedia of human behavior (Vol. 4, pp. 71-81). New York: Academic Press.

Bandura, A., \& Schunk, D. H. (1981). Cultivating competence, self-efficacy, and intrinsic interest through proximal self-motivation. Journal of Personality and Social Psychology, 41, 586-598.

Boyatzis, R. E. (2008). Competencies in the 21st century. Journal of Management Development, 27(1), 5-12. doi:10.1108/02621710810840730

Brandstädter, S., \& Sonntag, K. (2016). Interdisciplinary collaboration: How to foster the dialogue across disciplinary borders? In B. Deml, P. Stock, R. Bruder, \& C. Schlick (Eds.), Advances in ergonomic design of systems, products and processes (pp. 395410). Berlin: Springer.

Bromme, R. (2000). Beyond one's own perspective: The psychology of cognitive interdisciplinarity. In P. Weingart \& N. Stehr (Eds.), Practising interdisciplinarity (pp. 115-133). Toronto: University of Toronto Press.

Bronstein, L. R. (2003). A model for interdisciplinary collaboration. Social Work, 48, 297306. doi: $10.1093 / \mathrm{sw} / 48.3 .297$

Bunderson, J. S. (2003). Team member functional background and involvement in management teams: direct effects and the moderating role of power centralization. Academy of Management Journal, 46, 458-474.

Campion, M. A., Medsker, G. J., \& Higgs, A. C. (1993). Relations between work group characteristics and effectiveness: Implications for designing effective work groups. Personnel Psychology, 46, 823-850. 
Cheung, S. Y., Gong, Y., Wang, M., Zhou, L. B., \& Shi, J. (2016). When and how does functional diversity influence team innovation? The mediating role of knowledge sharing and the moderation role of affect-based trust in a team. Human Relations, 69 , 1-25. doi:10.1177/0018726715615684

Clark, H. H. (1996). Using language. Cambridge, UK: Cambridge University Press.

Cronin, M. A., \& Weingart, L. R. (2007). Representational gaps, information processing, and conflict in functionally diverse teams. Academy of Management Review, 32, 761-773

Cummings, J. N., \& Kiesler, S. (2008). Who collaborates successfully? Prior experience reduces collaboration barriers in distributed interdisciplinary research. Paper presented at the Computer Supported Cooperative Work, San Diego, California.

Devlieger, I., \& Rosseel, Y. (2017). Factor score path analysis: an alternative for SEM? Methodology, 13, 31-38. doi:10.1027/1614-2241/a000130

Eby, L. T., \& Dobbins, G. H. (1997). Collectivistic orientation in teams: an individual and group-level analysis. Journal of Organizational Behavior, 18, 275-295.

Eisenhardt, K. M., \& Graebner, M. E. (2007). Theory building from cases: Opportunities and challenges. Academy of Management Journal, 50(1), 25-32.

Epstein, S. L. (2005). Making interdisciplinary collaboration work. In S. J. Derry, C. D. Schunn, \& M. A. Gernsbacher (Eds.), Interdisciplinary collaboration. An emerging cognitive science (pp. 245-263). New York: Lawrence Erlbaum Associates.

Ericsson, K. A., \& Simon, H. A. (1993). Protocol analysis: Verbal reports as data. Cambridge: MIT Press.

Flanagan, J. C. (1954). The critical incident technique. Psychological Bulletin, 51, 327-359. doi: $10.1037 / \mathrm{h} 0061470$ 
Halfhill, T. R., \& Nielsen, T. M. (2007). Quantifying the "softer side" of management education: an example using teamwork competencies. Journal of Management Education, 31(1), 64-80.

Heidemeier, H., \& Moser, K. (2009). Self-other agreement in job performance ratings: A meta-analytical test of a process model. Journal of Applied Psychology, 94, 353-370. doi:10.1037/0021-9010.94.2.353

Hertel, G., Konradt, U., \& Orlikowski, B. (2004). Managing distance by interdependence: Goal setting, task interdependence, and team-based rewards in virtual teams. European Journal of Work and Organizational Psychology, 13(1), 1-28. doi:10.1080/13594320344000228

Koch, A., Strobel, A., Kici, G., \& Westhoff, K. (2009). Quality of the critical incident technique in practice: Interrater reliability and users' acceptance under real conditions. Psychological Science Quarterly, 51, 3-15.

Krapp, A. (2002). Structural and dynamic aspecs of interest development: theoretical considerations from an ontogenetic perspective. Learning and Instruction, 12, 383409.

Lattuca, L. R., Knight, D. B., \& Bergom, I. M. (2012). Developing a measure of interdisciplinary competence for engineers. Paper presented at the Conference of the American Society for Engineering Education (ASEE), San Antonio, TX.

Ley, T., Lindstaedt, S. N., \& Albert, D. (2005). Supporting competency development in informal workplace learning. Paper presented at the Conference for Professional Knowledge Management, Kaiserslautern, Germany.

Lindell, M. K., \& Whitney, D. J. (2001). Accounting for common method variance in crosssectional research designs. Journal of Applied Psychology, 86, 114-121. doi:10.1037//0021-9010.86.1.114 
Marsh, H. W., Muthén, B., Asparouhov, T., Lüdtke, O., Robitzsch, A., Morin, A. J. S., \& Trautwein, U. (2009). Exploratory structural equation modeling, integrating CFA and EFA: Application to students' evaluations of university teaching. Structural Equation Modeling, 16, 439-476. doi:10.1080/10705510903008220

Maynard, M. T., \& Gilson, L. L. (2014). The role of shared mental model development in understanding virtual team effectiveness. Group \& Organization Management, 39, 332. doi:10.1177/1059601113475361

Maynard, M. T., Mathieu, J. E., Rapp, T., \& Gilson, L. L. (2012). Something(s) old and something(s) new: Modeling drivers of global virtual team effectiveness. Journal of Organizational Behavior, 33, 342-365. doi:10.1002/job.1772

Morin, A. J. S., Marsh, H. W., \& Nagengast, B. (2013). Exploratory structural equation modeling. In G. R. Hancock \& R. O. Mueller (Eds.), Structural equation modeling: A second course (pp. 395-437). Charlotte, NC: Information Age Publishing, Inc.

Newell, W. H. (2001). A theory of interdisciplinary studies. Issues in Integrative Studies, 19, $1-25$.

Reich, S. M., \& Reich, J. A. (2006). Cultural competence in interdisciplinary collaborations: A method for respecting diversity in research partnerships. American Journal for Community Psychology, 38, 51-62. doi: 10.1007/s10464-006-9064-1

Repko, A. F., Szostak, R., \& Buchberger, M. P. (2014). Introduction to interdisciplinary studies. Los Angeles, CA: Sage.

Rogers, Y., Scaife, M., \& Rizzo, A. (2005). Interdisciplinarity: An emergent or engineered process? In S. J. Derry, C. D. Schunn, \& M. A. Gernsbacher (Eds.), Interdisciplinary Collaboration (pp. 265-286). Mahwah, NJ: Lawrence Erlbaum.

Sandberg, J. (2000). Understanding human competence at work: An interpretative approach. Academy of Management Journal, 43(1), 9-25. 
Steinheider, B., Bayerl, P. S., Menold, N., \& Bromme, R. (2009). Entwicklung und Validierung einer Skala zur Erfassung von Wissensintegrationsproblemen in interdisziplinären Projektteams (WIP) [Development and validation of a scale for knowledge integration problems in interdisciplinary teams]. Zeitschrift für Arbeitsund Organisationspsychologie, 53, 121-130. doi:10.1026/0932-4089.53.3.121

Stevens, M. J., \& Campion, M. A. (1994). The knowledge, skill, and ability requirements for teamwork: Implications for human resource management. Journal of Management, $20,503-530$.

Sung, N. S., Gordon, J. I., Rose, G. D., Getzoff, E. D., Kron, S. J., Mumford, D., . . Kopell, N. J. (2003). Educating future scientists. Science, 301, 1485. doi:t10.1126/science.10866133

Szostak, R. (2002). How to do interdisicplinarity: Integrating the debate. Issues in Integrative Studies, 20, 103-122.

van Ginkel, W. P., \& van Knippenberg, D. (2008). Group information elaboration and group decision making: The role of shared task representations. Organizational Behavior and Human Decision Processes, 105, 82-97. doi:10.1016/j.obhdp.2007.08.005

van Knippenberg, D., De Dreu, C. K. W., \& Homan, A. C. (2004). Work group diversity and group performance: An integrative model and research agenda. Journal of Applied Psychology, 89, 1008-1022. doi:10.1037/0021-9010.89.6.1008 


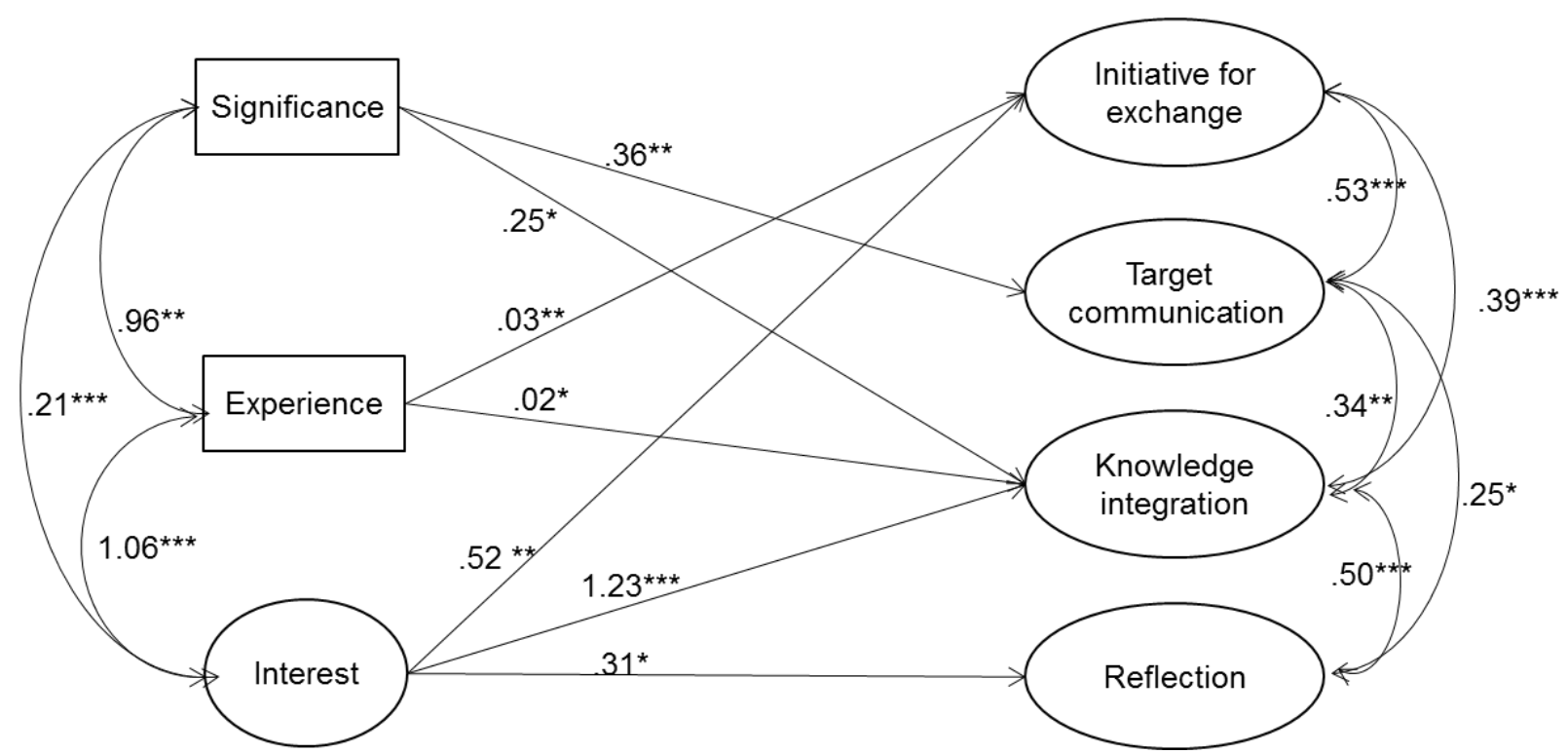

Figure 1. Study 2: Path diagram of influencing factors (significance of interdisicplinarity for the job, experience in years, and interest in interdisciplinary work) and interdisciplinary competencies. Unstandardized coefficients. Model fit: $\chi^{2}=133.77$; $\mathrm{df}=106$; CFI $=.983$; TLI $=.972 ; \mathrm{RMSEA}=.029 ; \mathrm{SRMR}=.030$ 
Table 1

Study 1: Initial Model of Interdisciplinary Competency based on Qualitative Requirement Analysis

\begin{tabular}{lll}
\hline Dimension & Behavioural Indicators & Summary of a Representative Incident \\
\hline Initiative for & - Making suggestions & $(-)$ Transdisciplinary project in distant \\
exchange & - proposing solutions & cooperation. Goal: develop a lifeline with \\
& - initiating concrete discussions & sensors for fire fighters. One project partner \\
& - abstract interactions $(-)$ & developed the lifeline, the other the sensors. \\
& - giving up $(-)$ & After months of separate work, partners meet \\
& - waiting for others to act $(-)$ & and show their prototypes. The lifeline was \\
& & too thin to fit the sensors. Afterwards people \\
& & laughed it off and decided to talk and meet \\
& more
\end{tabular}

$\begin{array}{ll}\text { Target group- } & - \text { Flexible adjustment to different } \\ \text { specific } & \text { audiences } \\ \text { communication } & - \text { bringing stakeholders on board } \\ - & \text { translating between disciplines } \\ - & \text { patience in explaining } \\ - & \text { communicate on different levels of } \\ & \text { abstraction }(-) \\ - & \text { force own opinion on others }(-)\end{array}$

Knowledge - Search for connections

integration - intellectual curiosity

- openness to others' arguments

- active integration
Although she is not a lawyer herself, the acting person likes to deal with legal texts and can also understand them in terms of content. She can then convey the contents of the legal texts to colleagues. She likes to communicate with and interpret between authorities, lawyers and colleagues.

A mechanical engineer conducts a joint project with sociologists and economists. In the corresponding discussions between the project members, it becomes clear how differently the disciplines methodically approach a topic. The members have prejudices against the other methods: "What you do is not research, just trial and error. This is like tinkering!", says one of them. The acting person manages to open up to the arguments of the other disciplines without losing sight of her own methods. Also, others start to use some of her ideas and methods.

Conference on engineering education. Interdisciplinary field with researchers from different disciplines. One presentation dealt with a study on student motivation; however, the operationalization was faulty, according to the informant. Difficult situation: how to uphold own quality criteria without to condemn procedures from other disciplines.

\author{
Reflection and - Realizing own limits \\ - uphold own quality criteria \\ - accepting others' premises \\ - taking different approaches and \\ methods seriously \\ - lower own standards (-) \\ - ignore methods of own discipline (-) \\ - consider the other as incompetent \\ $(-)$ \\ - take credit for others' achievements \\ $(-)$
}

\footnotetext{
Note. (-) refers to a negative behavioural indicator or an incident with a negative interdisciplinary outcome. Additionally derived dimensions cooperation skills, negotiation skills, networking, basic communication, meeting management, and professional expertise were not included in the model due to their lacking specificity for interdisciplinarity.
} 
Table 2

Study 2: Factor Loadings of the Confirmatory Factor Analysis and Descriptive Item Statistics of Manifest Variables for the Final Item Set

$\begin{array}{ll}\text { No. Item text } & \begin{array}{l}\text { Factor } M \\ \text { loading }\end{array}\end{array}$

Initiative for exchange

01 It is easy for me to make specific suggestions in order to create a $\quad \begin{array}{lll}.77^{\star * *} & 3.48 & 1.06\end{array}$ basis for discussion in an interdisciplinary team.

$02^{\mathrm{a}}$ Often, I am the person who has the ideas for interdisciplinary projects. $\begin{array}{llll}.58^{* * *} & 2.82 & 1.32\end{array}$

03 It is easy for me to take the initiative in an interdisciplinary meeting. $\begin{array}{lll}.58^{\star * *} & 3.16 & 1.31\end{array}$

Target group-specific communication

$04^{\mathrm{a}}$ In interdisciplinary teams, it is difficult for me to avoid unnecessary $\begin{array}{lll}.41^{* * *} & 3.10 & 1.21\end{array}$ technical terms.

05 In interdisciplinary teams, I find it difficult to get my point across. $\quad \begin{array}{llll}.68^{* * *} & 3.63 & 1.02\end{array}$

06 It is not a problem for me to adapt my language so everyone in an $\begin{array}{lll}.61^{\star \star *} & 3.64 & 1.10\end{array}$ interdisciplinary team understands.

07 Regarding language, I find it hard to engage with team members from $.50^{\star * *} \quad \begin{array}{lll}3.71 & 1.14\end{array}$ different disciplinary backgrounds.

Knowledge integration

$08^{\mathrm{a}} \quad$ In interdisciplinary work, I am good at connecting and integrating $\quad \begin{array}{llll}.82^{* * *} & 3.90 & .89\end{array}$ knowledge from different disciplines.

09 In interdisciplinary teams, I succeed in connecting different disciplines $\quad .75^{\star * *} \quad 3.89 \quad .85$ content-wise.

10 In interdisciplinary teams, I can easily comprehend what other $\quad \begin{array}{llll}.57^{* * *} & 3.51 & .86\end{array}$ members work on with regards to content.

Reflection

11 I uphold the quality criteria of my own discipline in interdisciplinary $\begin{array}{lll}.48^{* * *} & 3.93 & .91\end{array}$ teams.

12 I can very precisely name the questions my discipline is in charge of $\quad .80^{\star \star *} \quad \begin{array}{lll}3.83 & 1.02\end{array}$ and how my discipline differs from others.

$\begin{array}{lllll}13^{\mathrm{a}} \quad \text { I can very precisely name the methodological and content-related } & .75^{* * *} & 3.93 & .97\end{array}$ features of my discipline.

Notes. $N=315$; Factor loadings show loading of the manifest variable on the latent variable of each dimension; standardized coefficient; Model fit of CFA: Chi²-test of model fit: $91.72, d f=59, p=.004$; RMSEA $=.042 ; \mathrm{CFI}=.967 ; \mathrm{TLI}=.956 ;$ SRMR $=.043$.

6 -point rating scale from 0 to $5 ;^{a}=$ item was used as reference item for the ESEM-within-CFA approach. 
Table 3

Study 2: Geomin Rotated Factor Solution of ESEM Model with Final Itemset

\begin{tabular}{|c|c|c|c|c|}
\hline Item no. & $\begin{array}{l}\text { F1: } \\
\text { Initiative for } \\
\text { exchange }\end{array}$ & $\begin{array}{l}\text { F2: } \\
\text { Target } \\
\text { communication }\end{array}$ & $\begin{array}{l}\text { F3: } \\
\text { Knowledge } \\
\text { integration }\end{array}$ & $\begin{array}{l}\text { F4: } \\
\text { Reflection }\end{array}$ \\
\hline 01 & $.57^{\star \star}$ & -.03 & .25 & .04 \\
\hline $02^{a}$ & $.71^{\star \star}$ & .03 & -.04 & .01 \\
\hline 03 & $.41^{\star \star}$ & .11 & $.35^{\star \star}$ & $-.14^{*}$ \\
\hline $04^{a}$ & -.21 & $.65^{\star \star}$ & .01 & -.05 \\
\hline 05 & -.13 & $.49^{\star *}$ & .10 & .04 \\
\hline 06 & .11 & $.49^{\star \star}$ & .06 & .02 \\
\hline 07 & .03 & $.54^{\star \star}$ & -.11 & .13 \\
\hline $08^{\mathrm{a}}$ & .05 & -.04 & $.82^{\star \star}$ & .01 \\
\hline 09 & -.02 & .02 & $.71^{\star \star}$ & .05 \\
\hline 10 & -.02 & .09 & $.52^{\star \star}$ & .05 \\
\hline 11 & -.02 & .05 & -.01 & $.48^{\star *}$ \\
\hline 12 & .03 & -.01 & .06 & $.74^{\star \star}$ \\
\hline $13^{a}$ & -.01 & .02 & .01 & $.76^{\star \star}$ \\
\hline
\end{tabular}

Notes. Standardized coefficients. Model fit: Chi'-test of model fit: $45.38, d f=32, p=.06$; RMSEA $=.036 ; \mathrm{CFI}=.987 ; \mathrm{TLI}=.968 ; \mathrm{SRMR}=.022$.

$\mathrm{F}=$ factor loadings for each factor.

${ }^{* *} p<.01 ;{ }^{*} p<.05 ;{ }^{a}$ item was used as reference item for the ESEM-within-CFA approach 
Table 4

Study 2: Correlation of Study Variables

\begin{tabular}{|c|c|c|c|c|c|c|c|c|}
\hline & Measure & 1. & 2. & 3. & 4. & 5. & 6. & 7. \\
\hline 1. & Initiative for exchange & .66 & $.58^{* \star *}$ & $.75^{\star \star *}$ & $.38^{\star \star \star}$ & $.55^{\star \star \star}$ & $.35^{\star \star \star}$ & $.40^{* \star \star}$ \\
\hline 2. & $\begin{array}{l}\text { Target group-specific } \\
\text { communication }\end{array}$ & $.33^{* *}$ & .64 & $.53^{* * *}$ & $.37^{\star \star *}$ & $.34^{* \star *}$ & $.34^{* * *}$ & $.15^{\star}$ \\
\hline 3. & Knowledge integration & $.53^{\star *}$ & $.35^{\star *}$ & .75 & $.53^{\star \star \star}$ & $.34^{\star \star *}$ & $.40^{\star * *}$ & $.26^{\star \star \star}$ \\
\hline 4. & Reflection & $.24^{* *}$ & $.24^{\star *}$ & $.40^{* *}$ & .71 & $.21^{\star \star}$ & .07 & $.17^{\star \star}$ \\
\hline 5. & Interest in interdisciplinary work & $.37^{* *}$ & $.23^{* *}$ & $.48^{* *}$ & $.16^{* *}$ & .78 & $.46^{\star \star \star}$ & $.24^{\star \star \star}$ \\
\hline 6. & Significance & $.29^{* *}$ & $.27^{\star *}$ & $.36^{\star *}$ & .06 & $.38^{* *}$ & - & $.18^{* * *}$ \\
\hline \multirow[t]{3}{*}{7.} & Experience in years & $.34^{* *}$ & .10 & $.22^{* *}$ & $.13^{*}$ & $.17^{* *}$ & $.18^{* *}$ & - \\
\hline & M & 4.15 & 4.52 & 4.76 & 4.89 & 4.80 & 4.49 & 7.92 \\
\hline & $S D$ & .95 & .78 & .71 & .77 & .88 & .75 & 7.17 \\
\hline
\end{tabular}

Notes. $N=315$, table shows correlations between manifest variables; are shown below the diagonal and correlations between latent variables according to the CFA-model are shown above the diagonal. Cronbach's alpha is shown in the diagonal.

${ }^{*} p<.05 ;{ }^{* *} p<.01$. 
Table 5

Study 3: Correlations between Interdisciplinary Competencies and Convergent Measures

\begin{tabular}{llllll}
\hline $\begin{array}{l}\text { Interdisciplinary } \\
\text { Competencies }\end{array}$ & $\begin{array}{l}\text { Interest in } \\
\text { interdisciplin } \\
\text { ary work }\end{array}$ & $\begin{array}{l}\text { Preference } \\
\text { for } \\
\text { teamwork }\end{array}$ & $\begin{array}{l}\text { Teamwork } \\
\text { self-efficacy }\end{array}$ & $\begin{array}{l}\text { Managerial } \\
\text { Support }\end{array}$ & $\begin{array}{l}\text { Task Inter- } \\
\text { dependence }\end{array}$ \\
\hline Initiative for exchange & $.42^{* * *}$ & $.27^{* * *}$ & $.64^{* * *}$ & .07 & $.33^{* * *}$ \\
Target group-specific & $.35^{* * *}$ & $.22^{* * *}$ & $.36^{* * *}$ & $.23^{* * *}$ & $.15^{*}$ \\
$\begin{array}{l}\text { communication } \\
\text { Knowledge integration }\end{array}$ & $.56^{* * *}$ & $.19^{* *}$ & $.64^{* * *}$ & $.19^{* *}$ & $.27^{* * *}$ \\
Reflection & .12 & .09 & $.36^{* * *}$ & .06 & $.18^{* *}$ \\
\hline
\end{tabular}

Notes. $\mathrm{N}=447$; correlations between latent variables according to the ESEM-model. Standardized coefficients. Model fit for model with interest, preference and self-efficacy: Chi²-test of model fit: $278.57, d f$ $=161, p=.00 ; \mathrm{RMSEA}=.040 ; \mathrm{CFI}=.964 ; \mathrm{TLI}=.949 ; \mathrm{SRMR}=.038$. Model fit for model with managerial support and interdependence: Chi $^{2}$-test of model fit: $188.81 ; d f=110 ; \mathrm{CFI}=.97 ; \mathrm{TLI}=.95 ; \mathrm{RMSEA}=$ $.04 ; \mathrm{SRMR}=.04$

${ }^{*} p<.05 ;{ }^{* *} p<.01 ;{ }^{* \star *} p<.001$. 
Table 6

Study 3: Regression of General Team Competencies and Interdisciplinary Competencies on Team Effectiveness and Team Satisfaction

\begin{tabular}{|c|c|c|c|c|}
\hline \multirow{2}{*}{ Predictors } & \multicolumn{2}{|c|}{ Effectiveness } & \multicolumn{2}{|c|}{ Team Satisfaction of } \\
\hline & Self-rated & Peer-rated & Target person & Peer \\
\hline \multicolumn{5}{|l|}{ Model 1} \\
\hline \multicolumn{5}{|l|}{ General team competencies } \\
\hline Conflict resolution & .17 & .63 & .18 & .24 \\
\hline Collaborative problem solving & -.62 & -.81 & -1.04 & -.07 \\
\hline Communication & .29 & 1.20 & $1.17^{*}$ & .38 \\
\hline Goal setting and performance management & 1.28 & 1.15 & 1.40 & .58 \\
\hline Planning and task coordination & -.76 & .66 & .16 & -.16 \\
\hline Meeting management skills & .08 & -2.24 & -1.32 & -.60 \\
\hline Total $R^{2}$ & $.14^{* \star *}$ & .07 & $.07^{\star *}$ & .08 \\
\hline \multicolumn{5}{|l|}{ Model 2} \\
\hline \multicolumn{5}{|l|}{ General team competencies } \\
\hline Conflict resolution & .23 & .58 & .26 & .32 \\
\hline Collaborative problem solving & -.71 & -.63 & $-1.22^{*}$ & -.26 \\
\hline Communication & .24 & 1.03 & $1.04^{*}$ & .39 \\
\hline Goal setting and performance management & 1.26 & .91 & 1.44 & .78 \\
\hline Planning and task coordination & -.70 & .62 & .14 & -.25 \\
\hline Meeting management skills & -.03 & -2.13 & -1.26 & -.65 \\
\hline \multicolumn{5}{|l|}{ Interdisciplinary competencies } \\
\hline Initiative for exchange & .04 & .11 & .01 & .03 \\
\hline Target group-specific communication & $.13^{\star \star}$ & .05 & $.24^{\star * *}$ & .15 \\
\hline Knowledge integration & $.15^{\star *}$ & $.22^{*}$ & $.21^{* * *}$ & .08 \\
\hline Reflection & .09 & -.10 & -.06 & -.08 \\
\hline Total $R^{2}$ & $.21^{* * *}$ & $.14^{*}$ & $.17^{* * *}$ & $.12^{*}$ \\
\hline$\Delta R^{2}$ & $.06^{\star * *}$ & .05 & $.10^{\star \star *}$ & .03 \\
\hline
\end{tabular}

Notes. Standardized regression weights based on factor scores. ${ }^{*} p<.05 ;{ }^{* *} p<.01 ;{ }^{* \star *} p<.001$. 